\title{
MITO Y TRAGEDIA II: LAS DANAIDES O LA ARMONÍA ENTRE LOS SEXOS
}

Jose María Lucas

UNED

En la línea metodológica que ya he seguido en algún trabajo anterior ${ }^{1}$, intento hacer ahora un acercamiento al tratamiento que Esquilo dio al mito de las Danaides. En este breve preámbulo sólo querría detenerme a destacar el carácter evolutivo que tiene el relato mítico en la cultura griega, de forma que si uno quiere obtener una visión precisa de un mito concreto deberá tener siempre presente las posibles alteraciones a que ha podido estar sujeto. Y no me estoy refiriendo aquí a las alteraciones en puntos concretos, sino a los siempre posibles cambios de la interpretación última. Tal vez a la luz de este criterio general previo se solucionen las dificultades con que una y otra vez ha chocado la crítica.

\section{DESCRIPCIÓN GENERAL DEL MITO}

El rey egipcio Belo estaba doblemente emparentado con deidades en relación con el agua: era hijo de Posidón y de la ninfa Libia - no hay que pasar por alto, de otro lado, que Libia es hija de Epafo y, por lo tanto, nieta de Io, la muchacha argiva amada por Zeus y, consiguientemente, objeto de las iras de Hera; de esta forma, vemos cómo el posterior Dánao y

' Cf. J. M." LuCAS, «Mito y Tragedia: Hipólito y Fedra, dos vidas rebeldes", EPOS, 5, $1989,35-56$. 
sus hijas,' las Danaides, están en relación con Argos antes, incluso, de su huida a esa ciudad griega - y, de otra parte, se casó con Anquínoa, hija del dios Nilo. Belo a su vez tuvo dos hijos: Egipto y Dánao, que se repartieron el reino paterno, quedándose Dánao con Libia. Ambos hermanos tuvieron de diferentes esposas 50 hijos cada uno: Egipto 50 varones, los Egipcios, y Dánao otras tantas hembras, las Danaides. Las fuentes mitográficas tardias ${ }^{2}$ suelen aludir a la aparición de un conflicto entre ambos por el poder ; y en relación con este motivo se habla también, en ocasiones, de un oráculo sobre el peligro de muerte que correría Dánao en caso de ceder a la pretensión de los Egipcios de casarse con sus hijas ${ }^{4}$. Sea como fuere, lo que sí recogen todas las fuentes es la determinación, obsesiva, de los Egipcios de casarse con sus primas y el rechazo, igualmente inquebrantable, de éstas a aceptar tales bodas. Consecuencia de este enfrentamiento es la huida de Dánao y sus hijas de suelo egipcio y su llegada, probablemente a través de Rodas, a Argos. Pero al poco llegan tras ellas nuevamente los apremiantes pretendientes a suelo argivo en busca de las pretendidas bodas, y en tal situación las muchachas y su padre buscan el apoyo del rey de la ciudad para poder hacer frente al peligro que las acosa.

Pero la situación va a cambiar. Primeramente, vemos a Dánao ocupar el trono de Argos, aunque, como viene sucediendo, hay todo un abanico de opciones sobre el momento y la forma de producirse el cambio en el poder'. Y luego, al fin, éste accede a que sus hijas se casen con los Egipcios, aunque ellas acuerdan previamente con su padre en secreto dar muerte a

${ }^{2}$ Los principales testimonios de este mito son: Apolodoro, Biblioteca, II 1.4-5; Higino, Fábulas, 168 y 170; escolio a Homero, Iliada, I 42 y a IV 171; escolio a Píndaro, Píticas, IX 194, 195a, 200, y a Nemeas, X 10a; escolio a Esqullo, Prometeo encadenado, 853a; escolio a EurípIDES, Hécuba, 886, y a Orestes, 871; Ovidio, Heroidas, XIV. Y, claro está, al lado de estas fuentes hay todo un bosque de alusiones circunstanciales sobre puntos particulares del relato (un ejemplo podría ser Pausanias: II 15.5; $16.1 ; 19.3$ ss.; $20.7 ; 21.1 ; 24.2 ; 25.4 ; 37.1-2$; 38.2, 4; III 12.2; VII 21.13; X 10.5, pasajes éstos en los que el geógrafo menciona de pasada datos concretos en relación con los lugares que va describiendo, razón por la cual una gran parte se encuentra en el libro segundo, dedicado a Corinto y su región, a la que pertenece Argos). De todas estas fuentes mencionan el motivo del enfrentamiento entre los hermanos: el escolio a la Ilíada, el correspondiente al Prometeo, Apolodoro e Higino.

${ }^{3}$ Por el contrario, en otro grupo de testimonios no se menciona esta circunstancia: por ejemplo - y esto es importante en nuestro caso-, en Las suplicantes de Esquilo, pieza que desarrolla la parte primera del mito, no aparece la más mínima referencia a tal enfrentamiento entre los hermanos, componente éste que en condiciones normales debería haber sido señalado.

4 Escolio a EurípIDes, Orestes, 872; escolio a Esquilo, Prometen encadenado, 853 a; escolio a Homero, lliada, I 42. Curiosamente tampoco este extremo es mencionado en la tragedia esquílea conservada.

${ }^{5}$ La explicación más elaborada la encontramos en PaUSANIAs, Il 19.3-4: Dánao disputó al rey de Argos el trono, y los argivos terminaron por concedérselo al primero cuando asistieron a la lucha de un lobo con un toro, jefe de una manada de vacas, en la que salió victorioso el lobo, puesto que los argivos asimilaron a Dánao con este animal, que se había criado lejos de ellos al igual que sucedia con Dánao. 
sus maridos en la misma noche de las bodas. A la mañana siguiente se hace pública la matanza, pero se descubre igualmente que ha habido una excepción: Hipermestra ha perdonado la vida a Linceo, su pareja; aunque luego hay divergencias sobre el motivo de tal comportamiento: unos testimonios hablan de que Linceo respetó la virginidad de la muchacha ${ }^{6}$; otros suponen que Hipermestra se enamoró de su primo correspondiente ${ }^{7}$; y finalmente está la variante de la Heroida XIV de Ovidio, donde se acude a la pietas y al timor como explicación del comportamiento de Hipermestra ${ }^{8}$.

En tal situación es comprensible que Dánao y sus hijas se sintieran defraudados con la insolidaridad de Hipermestra, a resultas de lo cual se tomarán medidas al respecto: se nos habla de que Dánao encerró en una prisión a la hija desobediente; 0 incluso de que fue sometida a juicio por tal desacato, pero que el pueblo de Argos la declaró inocente. Y tras esta compleja variedad de peripecias se llega al final del relato mítico. Una tradición ${ }^{10}$ nos habla de una reconciliación total: tanto entre los personajes humanos entre sí como entre éstos y los dioses. Apolodoro nos cuenta que Atena y Hermes, por orden de Zeus, purificaron a las Danaides y que, a continuación, Dánao volvió a unir a la pareja rebelde y en segundas bodas casó a sus restantes hijas con los vencedores en una competición atlética, dato éste del certamen atlético que ya testimonia Píndaro en un epinicio del año 474 a. C. ${ }^{11}$, unos 10 años anterior, por lo tanto, a la puesta en escena

- Apolodoro, Biblioteca, II 1.5; y escolio a Píndaro, Nemeas, X 6 (10a).

' Escolio a Esquilo, Prometeo encadenado, 853a; y escolio a Píndaro, Píticas, IX 112 (195a).

${ }^{\circledR}$ En esta Heroida Ovidio nos presenta a la muchacha encerrada en la cárcel por haber infringido la orden paterna, y desde allí escribe esta carta de amor a Linceo. Es interesante el trabajo de S. JÄKEL, "The 14th Heroid Letter of Ovid and the Danaid trilogy of Aeschylus», Mnemosyne, 26 (1973) 239-48, donde perfila una atractiva interpretación de esos dos conceptos de pietas y timor: el primero es el respeto sacrosanto que observa Hipermestra ante una ceremonia sagrada como es la del matrimonio, puesto que el cumplimiento del plan funesto de Dánao seria ir contra los dioses que intervienen en el rito nupcial; y el segundo, en correspondencia, es el temor ante el castigo divino en caso de faltar a las promesas contraidas en las bodas; además, Jäkel lo pone en relación con el mismo doblete de conceptos que Atena establece en el juicio contra Orestes en Las Euménides, 689ss.: $\varphi o ́ \beta o \zeta$ y $\sigma \hat{\varepsilon} \beta \alpha \varsigma$ serán garantía suficiente para mantener apartado al hombre de cometer injusticia; $y$, lógicamente, de este empleo en la Orestia sugiere su existencia también en la trilogia esquílea de Las Danaides, donde se une al criterio de los que suponen un juicio paralelo a Hipermestra (sobre este punto, cf. más abajo).

- Cf., en especial, la Heroida, XIV de Ovidio mencionada más arriba. También lo cuenta Apolodoro.

${ }^{10}$ Claramente ya antigua a juzgar por sus testimonios: Pindaro, Piticas, IX 112 ss.; BAQUILIDES, XI 73 ss.; HERÓDOTO, II 98; y prácticamente seguro, como veremos, el propio Esquilo.

"PIndaro, Piticas, IX 112 ss. Atractivo es el trabajo de R. P. Winnington-Ingram, (Pindar's ninth Pythian ode", BICS, 16 (1969) 9-15, donde al final intenta emparejar el tratamiento del mito de Apolo y Cirene en el poema pindárico con el de las Danaides en la 
de esta trilogía, en caso de aceptar la cronología sugerida por el famoso Papiro de Oxirrinco 2256, fr. 3, que tanto ha trastocado la cronología tradicionalmente aceptada de la producción esquílea ${ }^{12}$. Pero hay igualmente un grupo de la tradición que supone un final funesto para Dánao y sus hijas, en debida compensación a su sangriento comportamiento para con sus primos. Así, diversas fuentes nos hablan de la muerte violenta de Dánao; en ocasiones a manos de Linceo, que acaba incluso con la vida de las asesinas de sus hermanos; aunque Higino ${ }^{13}$ limita el trágico desenlace al padre y casa a las Danaides con argivos. Y dentro de esta segunda tradición es donde hay que colocar la variante mitográfica del famoso castigo a que fueron sometidas las sanguinarias muchachas en el mundo de ultratumba, al verse obligadas a tener que llenar infructuosamente de agua una vasija agujereada, lo que está en clara relación con toda esa serie de trabajos sin fin que en el mito se impone a diversos personajes en pago a su maldad mientras vivieron ${ }^{14}$.

\section{AlgunOS ELEMENTOS DE ESPECIAL INTERÉS}

Tras la descripción general presentada en el punto anterior voy a detenerme ahora a comentar algunas particularidades que, a mi juicio, tienen una importancia especial para una más completa y correcta comprensión de este mito. $Y$ ahora prestaré una atención precisa a la cronología, porque este parámetro nos va a permitir una precisión mayor a la hora de valorar las aportaciones de Esquilo en el proceso evolutivo de este relato heroico.

\subsection{Su relación con el agua}

En primer lugar, es incuestionable la relación de las Danaides con el agua. Numerosos testimonios nos hablan de su participación en la floración

trilogía esquilea, puesto que en ambos se trataria de poner de manifiesto que la relación amorosa debe construirse sobre la persuasión y no sobre la violencia; y como reflejo de tal paralelismo, tal vez consciente por parte de Esquilo unos años más tarde, estaría esa alusión al episodio de la prueba atlética para elegir a los segundos esposos de las Danaides.

${ }_{12}$ Un buen tratamiento de los diversos problemas en torno a este papiro puede verse en el capitulo I de A. F. Garvie, Aeschylus' Supplices. Play and Trilogy, Cambridge 1869, pp. 128. De forma más resumida, aunque más reciente, está en H. FRIIS JOHANSEN and E. W. WhitTLe, Aeschylus. The Suppliants, edited by..., Copenhague 1980, vol. I, pp. 21-25.

${ }_{13}$ Higino, Fábulas, 170.11 .

14 Un tratamiento sistemático de este punto puede consultarse en E. KEULS, The water carriers in Hades, Amsterdam 1974 (para la tradición literaria, cf. también A. RUIZ DE ELVIRA, Mitología Clásica, Madrid, Gredos, 1975, pp. 132-4). 
de fuentes en la «seca» Argos. La historia de Amimona, una de las cincuenta muchachas, es otro apoyo directo: el episodio erótico-amoroso de esta Danaide, sobre el que volveré al final, nos presenta de nuevo a una de estas muchachas ocupada en descubrir manantiales por encargo de su padre. Ahora bien, es de un gran interés la constatación de que este aspecto es destacado ya por Hesíodo, Fr. 128 M-W:

Así, pues, convienen en que la región es rica en agua, mientras que la ciudad está situada en un lugar sin agua, pero que tiene abundancia de pozos, que relacionan con las Danaides en la idea de que los descubrieron aquéllas. De este hecho depende también este verso:

De una Argos que sin agua estaba hicieron las Danaides una Argos abundante en agua ${ }^{15}$

A través de estos testimonios vemos cómo se pone a Dánao o a las Danaides, según las fuentes, en relación con la floración de pozos haciendo,

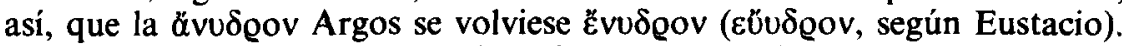
Se trata, pues, de unos personajes míticos que, desde su primera aparición - ya en Hesíodo; en los poemas homéricos no se recoge mención alguna a este área mítica-, aparecen en contacto con la naturaleza ${ }^{16}$.

\subsection{Su carácter amazónico}

Otro rasgo importante de las Danaides es su indiscutible carácter amazónico, que tal vez no ha sido valorado en su justa medida en la historia evolutiva de este relato mítico, pasándose de considerarlo un componente

${ }^{15}$ Doy arriba el texto que nos transmite EsTRABón, VIII 6.8 (en VIII 6.7 ha citado exactamente el mismo texto). Sin embargo, EustaCio, Comentarios a la Iliada, 461.2, menciona una variante del verso: «Muy sedienta llama a Argos... o también por la Danaides que vinieron de Egipto y enseñaron a perforar pozos, según Hesíodo: A Argos que sin agua estaba Dánao la hizo rica en agua». De cualquier forma, esta variación en la cita es indiferente para nuestro actual interés de destacar la relación de Dánao y sus hijas con el agua y, por lo tanto, con la Naturaleza. Utilizo la traducción de A. Martínez en Hesiodo. Obras y Fragmentos, Madrid, Biblioteca Clásica Gredos, 1978.

${ }_{16}$ Sobre la base de este testimonio la crítica en ocasiones ha supuesto que las Danaides son una derivación de deidades de la naturaleza del tipo de las ninfas o semejantes. 
central a posponerlo como una característica circunstancial. Y en este punto creo que la atención rigurosa a la evolución cronológica puede arrojar una luz importante a la hora de su más precisa interpretación en cada momento. En este sentido un testimonio destacado es el que nos aporta la Danaida, un poema épico tradicionalmente fechado en el siglo vi a. C. y cuya amplia extensión de 6.000 versos nos garantiza que en él se hacia una descripción pormenorizada de este mito. Pues bien, el Fr. 1 Bernabé es una breve cita transmitida por Clemente de Alejandría en la que encontramos a las Danaides armándose para un combate aún en suelo egipcio:

Cosas semejantes dice también el autor de la Danaida acerca de las hijas de Dánao, asi:

Y entonces se revestian con sus armas rápidamente las hijas de Dánao frente al rio de hermosa corriente, el soberano Nilo.

Es, pues perfectamente admisible suponer que en la versión completa del mito, o al menos en sus primeras etapas, tenía lugar un combate entre los Egipcios y las Danaides todavía en Egipto, antes de la huida de ellas a suelo argivo, y que el resultado de tal enfrentamiento armado fue no definitivo puesto que las muchachas no fueron sometidas a la voluntad de sus primos, sino que pudieron huir a Grecia. En cualquier caso, lo que es incuestionable es la presentación guerrera de las hijas de Dánao, como pone de manifiesto irrefutablemente la fuente ${ }^{17}$, y es además un apoyo decisivo para confirmar que en un primer momento estas heroínas presentaban una variante más del prototipo de las Amazonas, es decir, mujeres que llevan un tipo de vida más en consonancia con el característico de los hombres que con el de las mujeres: dedicación a la guerra, a la caza, en contacto con la naturaleza (recordemos el testimonio ya aludido de Hesíodo); y en tal contexto adquiere al momento una relevancia especial el rechazo amoroso que sienten las Danaides por sus primos, puesto que sabemos que un componente importante del prototipo amazónico es el rechazo a la unión amorosa con el varón, de tal forma que en estas primeras etapas del mito de las Danaides nos encontrariamos con que la oposición de las muchachas a casarse con sus primos obedecería más bien a una oposición previa y general

1 El contexto de Clemente de Alejandría no deja lugar a dudas de que el término «se revestian con sus armas» hay que entenderlo en el sentido concreto de prepararse para la lucha, y no en el figurado que sugirió Meyer (1982) de «equiparse para la travesia por mar». 
a todo contacto sexual con el sexo contrario, y no a un simple rechazo a unos pretendientes concretos de los que no estarian enamoradas.

Este rasgo de las Danaides termina desapareciendo en época tardía, como puede comprobarse bien en las fuentes del tipo de Apolodoro. Pero disponemos de algunos testimonios de que aún en el siglo $\mathrm{v}$ a. C. se tenía conciencia clara de esta característica. Así, por ejemplo, un fragmento conservado por Ateneo de un ditirambo de Melanípides, un poeta de la segunda mitad de ese siglo, nos vuelve a presentar a las Danaides dedicadas a una actividad esencialmente masculina, la caza ${ }^{18}$ :

Melanípides de Melos en el poema Las Danaides llama así al fruto "dátiles» (phoinicas) cuando hace la descripción de las propias Danaides:

... pues no presentaban aspecto de varones '...' , ni tampoco teniam al tipico de las mujeres, sino que montaban en carros de dos caballos por. los bosques soleados, disfrutando con frecuencia de la caza y otras veces buscando el incienso de sagradas lágrimas y los dátiles perfumados y la casia, dulces frutos de Siria.

Una nueva alusión a esta característica amazónica de las hijas de Dánao la encontramos igualmente en el v. 886 de la Hécuba de Eurípides, donde la anciana troyana, ante el desprecio que unos versos antes ha manifestado Agamenón sobre la valentía del género femenino, alude a las Danaides en paralelo a las mujeres de Lemnos, mujeres todas ellas que rechazaron violentamente a sus maridos en clara consonancia con el prototipo amazónico.

Pero en apoyo de este componente pueden aportarse más elementos. Por ejemplo: en el mito de las Danaides observamos que Atena ocupa un lugar preferente, pues la vemos guiando a las acosadas muchchas en su huida de suelo egipcio a Grecia y, probablemente en agradecimiento, ellas le dedican un altar en su paso por Rodas camino de Argos. Pues bien, no olvidemos que Atena representa una esfera vital totalmente apartada de las relaciones entre los sexos: no nace de la unión amorosa de un ser masculino y otro femenino, sino sólo de la cabeza de Zeus; además, nunca tiene contacto con varón.

* La fuente nos certifica que el poema era sobre las Danaides, a las que se está describiendo en estas líneas. El fragmento está recogido en los Poetae melici Graeci de Page, con el núm. 757. El estado del texto de las dos primeras líneas está bastante deteriorado, aunque suficiente para nuestros intereses aquí. Para los problemas de crítica textual, cf. G. GIANGRANDE, "Interpretationen Griechischer Meliker», $R h M, 114,1971,118-24$. 
De otro lado, es también estrecha su relación con Ártemis, la diosa de la caza y de la vida en la naturaleza, lejos igualmente del contexto de las relaciones sexuales: el mito de Hipólito es claro en este sentido y, curiosamente, este héroe es hijo de una amazona.

Después de los testimonios expuestos parece dificil rechazar que en una primera etapa del mito de las Danaides el componente amazónico desempeñaba un papel importante en la caracterización de nuestras heroínas. Y tampoco puede rechazarse que en Las suplicantes de Esquilo hay varios pasajes que dejan traslucir esta vieja característica ${ }^{19}$. Ahora bien, no es menos cierto que en la tragedia esquílea nos encontramos ya con unas muchachas en lo fundamental plenamente próximas al tipo femenino convencional, o sea, débiles, que no hacen frente al varón, sino que solicitan la ayuda de otros hombres para escapar de la unión con unos pretendientes, sus primos, a los que no quieren.

\subsection{La salida de la matanza}

Otro punto importante en este relato mítico es el inmediatamente posterior al descubrimiento de la matanza de los Egipcios a manos de sus esposas - y ello tendrá una incidencia especial en lo que se refiere a Esquilo, como veremos, a la hora de intentar precisar, en la medida de lo posible, la acción dramática de la trilogía que escribió sobre este tema mítico--: un grupo de fuentes nos hablan de que, una vez llevada a cabo la matanza nocturna, tuvo lugar un juicio como salida a la situación creada por la actuación insolidaria de Hipermestra, aunque, como suele suceder, dentro de este grupo hay a su vez diversas variantes en los detalles.

El testimonio más claro nos lo proporciona Pausanias ${ }^{20}$ : Dánao acusa formalmente a Hipermestra de desobediencia, pero los argivos la absuelven de toda culpa. Realmente ya el propio Eurípides ${ }^{21}$, en una época mucho más próxima a Esquilo, hace una breve alusión a este punto afirmando que Dánao dio satisfación judicial a su hermano Egipto por la muerte de los hijos de éste ${ }^{22}$. Los escolios al pasaje euripídeo ${ }^{23}$ entran en mayores por-

${ }^{19}$ Por ejemplo: vv. 8-10; 392s.; 1031 ss. Ultimamente el rechazo a admitir tales elementos en la versión esquilea ha venido principalmente de J. K. MAckINNON, "The reason for the Danaids' flight», $C Q, 28,1978,74-82$., y de H FRIIS JOHANSEN-E. W. WhITtLe, op. cit., en nota 12 , pp. 29 ss.

${ }^{20}$ PaUSAnias, II 19.6; II 20.7; II 21.1 .

${ }^{21}$ EURíPIDES, Orestes, 872-873.

${ }_{22}$ Por EuRIPIDES, Fr., 846, sabemos que para este otro trágico Egipto habia llegado a Argos acompañando a sus hijos desde los primeros momentos.

${ }^{23}$ Escolios a EurípIDES, Orestes, 871 y 872. 
menores, aunque ello no significa que ésa fuese la versión del trágico: Egipto llega ahora dispuesto a vengar la afrenta, pero Linceo se interpone y convence a su padre de que lleve a juicio a Dánao.

Vemos, pues, que por encima de las variantes hubo una corriente de la tradición mitográfica que daba entrada a la celebración de un juicio en torno a la oportunidad del comportamiento de las Danaides, dada la excisión de Hipermestra, pues es claro que una de las dos partes había actuado mal: o bien la una por desobedecer, o bien las otras por llevar a la práctica unos planes asesinos. Y, en estas circunstancias, la crítica moderna, a la hora de intentar reconstruir la trilogía esquílea sobre este tema, ha supuesto en ocasiones que en la tercera pieza titulada precisamente Las Danaides como nos confirman diferentes fuentes ${ }^{24}$, Esquilo daba entrada a un debate judicial, en paralelo, piensan, al que tenemos en Las Euménides conservada a cerca de la oportunidad de la actuación matricida de Orestes.

\subsection{Los desenlaces}

Ya he dicho más arriba que hay una doble tradición general sobre el momento del desenlace final de este relato mítico: un final feliz y un final funesto. Pero conviene ahora entrar en un análisis más detallado que nos acerque de alguna manera a la versión que dio Esquilo para la Tragedia.

El desenlace funesto es el más extendido, sobre todo en la tradición tardía, y, como ya he señalado, dentro de él se inscribe la variante del castigo eterno de que son víctimas las Danaides en el Hades. Ahora bien, sería importante conseguir algún testimonio que nos certificase la antigüedad de esta salida. Pues bien, en este sentido disponemos de dos fuentes, pero en ambos casos su índice de seguridad es un tanto incierto. Veámoslo.

El Papiro de Oxirrinco $2487^{25}$ nos conserva un trozo del Catálogo de las mujeres de Hesíodo, y en las primeras líneas se está haciendo referencia al caso de Hipermestra, puesto que sabemos que Abante (lin. 3) es hijo de Linceo y de esta Danaide, y padre, a su vez, de Preto y Acrisio de su unión con Aglaya (lín. 8):

$$
\begin{aligned}
& v o v, \ddot{\varepsilon} \delta \omega x \varepsilon[\ldots . .] \alpha v[ \\
& -\overline{v v}-\overline{v v} \omega v \mu \varepsilon \gamma \alpha \dot{\lambda} \eta v[\dot{\alpha} \pi \varepsilon \tau \varepsilon i \sigma \alpha] \tau o \lambda \dot{\omega} \beta \eta v .
\end{aligned}
$$

${ }^{24}$ Cf. EsQuilo, Frs., 43-46.

${ }^{29}$ Hesiodo, Fr., 129 M-W. 


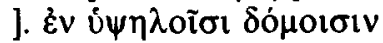

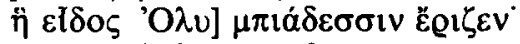

$\pi \alpha] \tau \grave{\eta} \varrho \dot{\alpha} v \delta \varrho \tilde{\omega} v \tau \varepsilon 9 \varepsilon \tilde{\omega} v \tau \varepsilon$

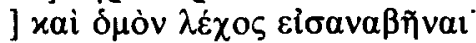

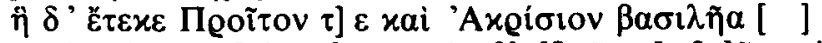

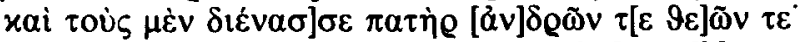

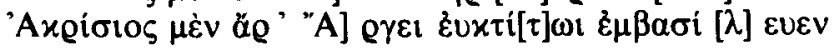

..., dio .... [vengó] una gran afrenta. ... luego [dio a luz] al irreprochable Abante ... en mansiones de altos techos ... [la cual en belleza] competia con las olimpicas. ... padre de los hombres y de los dioses ... y subir a lecho igual. [Ésta dio a luz a Preto] y al soberano Acrisio y el padre de los hombres y de los dioses [les concedió reinos diferentes]: [ Acrisio] reinó en la bien construida Argos ...

Evidentemente, sería importante para nuestros intereses saber quién es el sujeto de ese "vengó una gran afrenta". Lobel, el editor del papiro en la serie inglesa, pensó en Dánao y, de esta forma, el texto hesiódico estaría refiriéndose a la matanza de los Egipcios como venganza de Dánao en pago a haber llevado la peor parte en la querella con su hermano Egipto. Ahora bien, dada la inmediatez textual entre esta expresión y la alusión de Liceo e. Hipermestra en el verso siguiente como padres de Abante, sería tal vez más fácil suponer que el autor de la tal venganza es Linceo y, de esta manera, estaríamos asistiendo al primer testimonio de ese final funesto ya aludido y del que tenemos amplia documentación en épocas posteriores: Linceo venga la muerte de sus hermanos acabando con la vida de Dánao y, tal vez incluso, también con la de sus hijas. Sin embargo, el estado del papiro relega esta sugerencia a la categoría de posibilidad.

Disponemos igualmente de otro testimonio de fecha temprana: en el $F r$., $305 \mathrm{~W}$ de Arquíloco se nos dice:

Después de Inaco reinaron sobre los argivos Foroneo y muchos otros hasta el reinado de Linceo, que fue el que de entre las hijas de Dánao se casó con Hipermestra. El tal Linceo luchó con el rey Dánao y lo mató, apoderándose después del reino y de su hija, según escribió el muy sabio Arquíloco. 
Ahora bien, la fuente transmisora es Malalas, un cronógrafo del siglo vI d. C., y la crítica ha puesto en duda la certeza de la noticia ${ }^{26}$.

Frente a esta tradición de desenlace funesto nos encontramos desde época relativamente temprana una línea de final feliz, según la cual las Danaides obtienen la purificación de su acto de sangre y contraen además unas segundas y ya definitivas bodas. Esta variante es, al menos, tan antigua como Pindaro, Pítica IX, epinicio compuesto en el año 474 a. C., unos diez años, por lo tanto, anterior aproximadamente a la trilogía esquilea sobre este mito, si aceptamos la cronologia baja apoyada por el famoso Papiro de Oxirrinco 2256, fr. 3, ya mencionado ${ }^{27}$. En el pasaje aludido de Apolodoro se nos cuenta que Atena y Hermes, por orden de Zeus, purificaron a las Danaides y que, a continuación, Dánao volvió a unir a la pareja rebelde y en segundas bodas casó a sus restantes hijas con los vencedores en una competición atlética; pues bien, Píndaro, en la Pítica citada, hace alusión a esta prueba atlética establecida por Dánao, lo que supone admitir que él adoptaba igualmente este desenlace feliz de reconciliación total. Y por semejantes derroteros de un final feliz transitan Baquilides ${ }^{28}$ y Heródoto ${ }^{29}$.

Ante esta dualidad de desenlaces podemos asegurar prácticamente con total seguridad que Esquilo seguía la variante del desenlace afortunado, lo cual no plantea problemas cronológicos $\mathrm{y}$, además, entronca bien con ese planteamiento de reconciliación, tan típicamente esquíleo, entre la esfera divina y la humana, y de lo cual tenemos un ejemplo claro en el final de la trilogía conservada, la Orestía ${ }^{30}$. De otro lado, es imposible decidir si Píndaro, primera documentación conservada, fue el creador de esta variante: sabemos que el poeta trágico Frínico, en los primeros momentos de este siglo $v$ a. C. - antes, por lo tanto, que Píndaro-, escribió dos tragedias, tituladas respectivamente Los Egipcios y Las Danaides, en las que incuestionablemente trataba este área del mito; pero desconocemos el desenlace que presentaba, aunque sería sugestivo pensar que aquí, una vez más, la Tragedia fue la innovadora, con lo cual Esquilo no estaria más que siguiendo un camino ya iniciado por los primeros cultivadores de esta variante dramática.

26 Por ejemplo, West en su edición de Arquiloco lo coloca en el apartado de los Dubia.

${ }^{27}$ Cf. pp. 64 y nota 12 .

28 Baquílides, XI 73 ss.

29 HeRODOTO, II 98.

30 El Fr., 44 de Esquilo, sobre el que volveré más abajo, nos permite suponer con gran probabilidad la reconciliación final. 


\section{INTERPRETACIONES MODERNAS MÁS ACEPTADAS DEL MITO DE LAS DANAIDES}

En el capítulo quinto del libro de Garvie, mencionado más arriba ${ }^{31}$, sobre Las suplicantes de Esquilo puede consultarse una buena puesta al día de casi todo lo publicado sobre este mito hasta el final de los años sesenta, razón por la cual aquí voy sólo a detenerme a perfilar los grupos generales que durante ese período de tiempo gozaron de una mayor aceptación, para luego referirme a los principales trabajos aparecidos en las dos últimas décadas. Ahora bien, prescindiendo ahora de los particularismos de cada uno, a todos les caracteriza el no hacer una discriminación cronológica en el sentido que yo apuntaba en la parte primera de estas páginas, puesto que desde la perspectiva del hecho mítico es incuestionable en Grecia la existencia de una evolución en función de las épocas y de los autores, y dentro de este marco la incidencia de la Tragedia tuvo un peso especial. Todos los intentos de interpretación suelen tomar como fuente de referencia fundamentalmente Las suplicantes de Esquilo, que, como ya he dicho más arriba, es la tragedia conservada de la trilogía ligada que este poeta dramático escribió sobre este área del mito; pero, al tiempo, mezclan indiscriminadamente datos de otras fuentes, lo que en este caso ha llevado a una constante situación de confusionismo e incertidumbre.

Un primer bloque interpretativo ${ }^{32}$ es el que ve en este mito un rechazo genérico al varón, lo que supone ver en las Danaides una variante del prototipo amazónico ya comentado: las hijas de Dánao no sólo no desean casarse con sus primos los Egipcios, sino que su postura es más teórica por cuento que se oponen a todo contacto con el sexo opuesto. Los puntos de apoyo concretos en su argumentación son varios: es chocante que ninguna de las cincuenta muchachas esté enamorada de su pareja, si es que se trata simplemente de unos pretendientes no deseados; en la obra de Esquilo las acosadas Danaides invocan varias veces la ayuda de Ártemis, diosa que simboliza el estado de virginidad; más concretamente, en el v. 287 se las compara directamente con las Amazonas. Todas estas consideraciones son oportunas, pero no es menos cierto que la característica general de las Danaides en la tragedia esquílea no coincide con el esquema canónico de las Amazonas, puesto que las vemos débiles solicitando la ayuda externa para enfrentarse al peligro varonil que las persigue y acosa.

${ }^{31} \mathrm{Cf}$. nota 12.

${ }^{32}$ Importante por su acogida y que arranca ya del siglo pasado, entre cuyos detentadores más preeminentes está $U$. von Wilamowitz (cf. el libro ya mencionado de Garvie, en nota 12 para los pormenores bibliográficos). 
Ha habido varios intentos de interpretación por vía psicoanalítica. Hace algunos decenios Kouretas ${ }^{33}$ establecía que dentro de las tres etapas marcadas por Freud en el proceso del complejo femenino de castración (1: inhibición sexual; 2: cambio de carácter con la adopción de un complejo de masculinidad; y 3: normalización de la sexualidad) las Danaides se encontraban en el estadio segundo lógicamente. Por derroteros semejantes más recientemente Caldwell ${ }^{34}$ piensa que para Esquilo, como para Freud, una tarea esencial y continua del hombre es la lucha por liberarse a sí mismo del pasado, transcurrido bajo la tutela paterna, para encontrarse libre en un futuro, lo que equivaldrá a consolidarse como miembro de pleno derecho en la comunidad social; y en el caso de las Danaides esta transición del pasado al futuro está centrada en la transferencia del amor al padre al del esposo.

Con una base mayor en la realidad social griega de la época está la interpretación, ampliamente aceptada, de Thomson ${ }^{35}$ : las Danaides, al rechazar el matrimonio con los Egipcios que son, no lo olvidemos, primos suyos, representan una postura moderna de las relaciones intersexuales al abogar por unas relaciones exogámicas, mientras que los pretendientes representan la postura más arcaica endogámica, todo lo cual se ha tratado de basar en el entremado de relaciones jurídicas relativas al matrimonio en la Atenas contemporánea.

Ahora bien, la interpretación más aceptada es la de que las Danaides lo que verdaderamente rechazan es el acoso violento y la unión forzada con unos pretendientes no deseados, o dicho más llanamente: las hijas de Dánao no están dispuestas a casarse con los Egipcios porque no los quieren. Esta es la postura de K. von Fritz ${ }^{36}$. Ahora bien, no es menos cierto que si se lee con detenimiento la tragedia esquílea al menos, se observan repetidos brotes de un rechazo genérico al varón de corte amazónico, como ya he señalado, que crean un problema para esta interpretación de tipo personalistaamoroso. Para salir al paso de esta dificultad Winnington-Ingram ${ }^{37}$ ha sugerido una explicación psicológica: el acoso de los pretendientes es tal que lleva a las agobiadas muchachas en un momento dado a odiar incluso la institución del matrimonio, aunque no fuese ese su punto de partida. Se

${ }^{33}$ K. Kouretas, "Application de la psychanalyse à la mythologie: la névrose sexuelle des Danaides d'après les "Suppliantes" d'Eschyle", Revue française de Psychanalyse, 21, 1957, $597-602$.

34 R. S. CALDwell, "The psychology of Aeschylus' Supplices", Arethusa, 7, 1974, 45-70.

${ }^{35}$ G. D. Thomson, Aeschylus and Athens. A study in the social origins of drama. Londres, $1973^{4}$, pp. 285-295.

36 K. von FRITZ, «Die Danaidentrilogie des Aeschylus», Philologus, 91, 1936, 121-36 y 249 . 69 (= Antike und moderne Tragödie, Berlín 1962, pp. 160-92).

${ }^{37}$ R. P. WINNINGTON-INGRAM, "The Danaid trilogy of Aeschylus», JHS, 61, 1961, 141 52 (= Studies in Aeschylus, Cambridge 1983, pp. 55-72). 
trataria, pues, de una evolución a partir de una situación concreta hasta desembocar en una postura general. Pero, en mi opinión, esta sugerencia, que sería atractiva en un contexto normal, choca en este caso con la documentación a nuestra disposición, y a la que ya me he referido, de que previamente a Esquilo las Danaides responden preferentemente al prototipo amazónico.

Los trabajos aparecidos en los últimos 20 años, tras la monografia de Garvie, en buena medida vienen simplemente a reafirmar alguna de las opciones ya descritas mediante un análisis más detenido de los datos, aportando en ocasiones sugerencias nuevas.

Ireland ${ }^{38}$, en un intento de solucionar la aporía creada por esa serie de manifestaciones de un rechazo genérico al matrimonio en la pieza esquílea conservada, hace hincapié en que allí las Danaides son a un tiempo coro y protagonistas, lo que hace que las reflexiones generales de las muchachas en cuanto coro tienen que ser entendidas en el contexto a que ellas mismas dan lugar en cuanto protagonistas.

Ferrari $^{39}$, tras un detenido análisis de diferentes pasajes de la tragedia, concluye que la actuación de las Danaides es la reacción lógica a la violencia de los Egipcios y no un rechazo congénito al varón, en la línea, pues, que ya he descrito más arriba, aunque, de otro lado, enfatiza el componente amoroso que pone de manifiesto el Fr. 44, correspondiente a Las Danaides, tragedia perdida que formaba parte de la trilogía esquílea cuya pieza inicial era Las suplicantes conservada.

$\mathrm{Al}$ año siguiente MacKinnon ${ }^{40}$ hace un sintético, pero útil, estado de la cuestión y, al final, él mismo se inclina por la opción de la violencia de que son objeto las hijas de Dánao. Ahora bien, en las últimas páginas introduce una consideración a mi juicio interesante: frente a la postura de los Egipcios, que persiguen a las Danaides llevados del deseo de hacerlas de su propiedad y por un claro anhelo de lujuria, se yergue la propuesta deducible del Fr. 44 mencionado, en boca de Afrodita y sobre el que volveré más abajo, a cerca de la necesidad de una auténtica pasión amorosa entre las dos partes de toda relación sexual.

En la Introducción a la edición de Las suplicantes a cargo de Johansen y Whittle ${ }^{41}$ se concluye que el tema central de la tragedia esquílea conservada es «la protección del débil», sólo que este motivo adquiere una mayor profundidad por la ambivalencia de la circunstancia de que el grupo de muchachas indefensas está realmente compuesto por unas futuras asesinas, a

${ }^{38}$ S. IRELAND, "The problem of motivation in the Supplices of Aeschylus», RhM, 117 , 1974, 14-29.

39 F. FerRarı, "La misandria delle Danaidi», ASNP, 1977, 1303-21.

4 J. K. MacKinnon, "The reason for the Danaids' flight", $C Q, 28,1978,74-82$.

${ }^{4}$ H. Fris Johansen, E. W. Whittle, Aeschylus. The Suppliants, Copenhague 1980, vol. I, pp. $29-40$. 
lo cual se están constantemente haciendo alusiones irónicas más o menos claras. De otro lado, es el primer texto conocido en la historia de la civilización europea en que se plantea el problema de la unión matrimonial de mutuo acuerdo ${ }^{42}$.

Kraus $^{43}$ se une al grupo de los que ven en la actuación de las Danaides un rechazo general al matrimonio, ya sea con los Egipcios ya con cualquier otro varón. Pero añade que este rasgo del mito es una innovación de Esquilo, puesto que en las restantes fuentes se trata de un enfrentamiento derivado de la lucha previa entre los padres respectivos, Dánao y Egipto.

Sicherl ${ }^{44}$ sugiere que la razón última de la conducta de las Danaides radica en el oráculo amenazador contra su padre al que aluden algunas fuentes tardías ${ }^{45}$, llegando incluso a sugerir que este motivo de oráculo arranca realmente del propio Esquilo, puesto que de este modo es como la trama adquiría planteamiento trágico al debatirse las muchachas entre su inclinación natural y el amor filial.

Finalmente, Detienne ${ }^{46}$ intenta una explicación general del mito y concluye que en este caso asistimos a una explicación de la fundación del matrimonio, acto éste en el que la violencia desempeña un papel central. Pero tal vez es una interpretación en exceso generalizadora, que no repara en las posibles alteraciones que experimentó este relato, así como unifica categorías en un mismo momento, como cuando identifica la invención del matrimonio con el que éste se produzca de mutuo acuerdo entre el hombre y la mujer contrayentes. En cualquier caso, no repara en si Esquilo aportó o no algún elemento nuevo a la posible evolución de este relato mítico.

En resumen, de las interpretaciones hasta aquí dadas yo diría que, con las matizaciones aportadas por cada uno, siguen manteniéndose vigentes dos intentos generales de explicación: o bien el rechazo genérico al varón, o bien la oposición al casamiento con unos pretendientes no deseados. $Y$, a mi juicio, una y otra son oportunas por cuanto que cada una reproduce efectivamente una parte de la verdad, pero fallan al pretender dar una explicación única y homogénea a un relato que a todas luces ha experimentado una alteración en su evolución.

42 Los autores rechazan categóricamente los posibles elementos amazónicos existentes en la tragedia esquilea y, asi, se dedican a rebatir uno por uno los 10 pasajes en los que Garvie veia manifestaciones de tal tipo.

"3 W. Kraus, "Aischylos" Danaidentetralogie», en Aus allem Eines. Studien zur antiken Geistesgeschichte, Heidelberg 1984, pp. 85-137.

${ }_{4}^{4}$ M. SICHERL, «Die Tragik der Danaiden», $M H, 43,1986,81-110$.

$45^{\prime}$ Cf. p. 62 y nota 4.

4h M. DetienNe, «Les Danaïdes entre elles ou la violence fondatrice du mariage», Arethusa, $21,1988,159-75$. 


\section{LA INTERPRETACIÓN EVOLUTIVA Y LA VERSIÓN DE ESQUILO}

Como cierre de estas páginas intentaré en este punto último una aproximación personal al problema, basándome metodológicamente en un planteamiento evolutivo, o dicho de otra manera, en el criterio de que hay que tener muy en cuenta el proceso que experimenta el relato de un mito en la cultura griega ${ }^{47}$ a lo largo de su uso por los diferentes autores literarios, entre los cuales destaca la labor de los poetas, y de manera especial los poetas trágicos. A la luz de un planteamiento tal las cosas adquieren tal vez su explicación más precisa.

Sabemos por diversas fuentes que Esquilo escribió una tetralogía ligada sobre este mito, de la que afortunadamente conservamos la primera pieza, Las suplicantes. Tras ésta venían Los Egipcios y, cerrando la parte trilógica de tratamiento trágico, Las Danaides. Finalmente, en este caso el drama satírico de rigor también tenía que ver con el tema argumental de la parte anterior y se titulaba Amimona, sobre el que volveré más abajo.

A lo largo de las obras trágicas mencionadas Esquilo escenificaba el relato que más arriba he descrito con pormenor. Dado el estado fragmentario de las dos últimas piezas del conjunto trilógico no podemos precisar con mucha exactitud cómo llevaba a cabo su tarea, pero, no obstante, es posible determinar las líneas generales del argumento. En la obra conservada vemos a las hijas de Dánao llegar a Argos huyendo del acoso de sus primos, los Egipcios, y solicitar ayuda del rey Pelasgo, soberano de la ciudad argiva, el cual en el momento debido acude a solicitar el permiso debido a la Asamblea de los ciudadanos, prueba evidente de que en el tratamiento esquíleo está ausente la figura del rey con poder absoluto característico de la época verdaderamente monárquica. En respuesta a tal consulta el pueblo argivo acuerda defender a las atemorizadas muchachas de la persecución de que son objeto, y, así, esta primera pieza de la trilogía concluye con este compás de espera, aunque en las últimas tiradas de versos se oyen voces de admonición contra esta actitud de aparente rechazo de Afrodita. En la segunda tragedia debía de producirse una "aparente» reconciliación entre las dos partes, y fruto de ella era la celebración de las bodas, momento éste con el que debía de cerrarse la acción dramática, aunque de alguna manera se haría explícita la conjura del padre con sus hijas para acabar con la vida de los recientes esposos, como cuenta el mito. Esta matanza tendría lugar entre la segunda y la tercera pieza, de tal manera que esta última comenzaría con el descubrimiento de la matanza a la mañana siguiente de las bodas; al

${ }^{47}$ Cf. C. García Gual, La Mitologia. Interpretaciones del pensamiento mítico, Montesinos Editor, Barcelona 1987, cap. II, pp. 27-42. 
tiempo quedaria igualmente al descubierto la heterodoxia de Hipermestra y el problema consiguiente. Aquí algunos críticos suponen la celebración de un juicio, en paralelo al que sufre Orestes en Las Euménides conservada, aunque no disponemos de datos consistentes que confirmen tal reconstrucción. En cualquier caso, lo que sí es cierto con toda seguridad ${ }^{48}$ es que en algún momento de la pieza aparecía Afrodita, hablando lógicamente en favor de la actitud de Hipermestra ${ }^{49}$. En cualquier caso, la presencia de esta diosa supone que se llegaba a un final feliz, en el que las muchachas aceptaban los postulados amorosos de la diosa $y$, tras la debida purificación comentada por Apolodoro, se llegaría a la fijación incluso de unas segundas, y ya definitivas, bodas, ya comentadas en Píndaro, como he señalado, unos 10 años antes ${ }^{50}$.

Así las cosas, veamos ahora cuál fue el tratamiento que Esquilo dio a este mito. En primer lugar, vemos cómo nuestro trágico, en consonancia con su postura conciliadora entre la esfera divina y humana tantas veces comentada, vuelve aquí a dar un final feliz a la peripecia dramática, en contraste con los otros dos trágicos, en especial Sófocles. De esta forma Esquilo se separa de esa corriente que concluye el relato con un desenlace funesto y que, tal vez, arrancaba en Hesíodo, como ya he señalado más arriba. La primera documentación de final conciliador es el aludido epinicio de Píndaro, unos años antes de la adaptación esquílea; pero tal vez el poeta de Beocia lo tomó de la escenificación que antes había hecho Frínico, de la que también he hablado más arriba, en cuyo caso se debería una vez más a la Tragedia el cambio de giro en la conclusión de un relato mítico.

Ahora bien, aún nos queda por abordar la interpretación general del mito de las Danaides en Esquilo. Decia unas páginas antes que para Winnington-Ingram se trataba de una evolución a partir de un problema particular, el rechazo de unas muchachas que no están enamoradas de unos pretendientes concretos, hasta desembocar en una oposición genérica al matrimonio en cuanto tal debido a una desviación psicológica. Pues bien, a mi juicio el proceso es exactamente el contrario. A partir de un prototipo amazónico que muy probablemente presentaban las Danaides en los estadios iniciales del mito previo a Esquilo, se llega en este poeta trágico al planteamiento de un enfrentamiento, de corte mucho más moderno, en la eterna lucha entre los sexos en el sentido de si debe primar la imposición (sinónimo, en este caso, de violencia) o la armonía (sinónimo, aquí, de persuasión) entre

47. Cf. Esquilo, Fr. 44, sobre el que volveré más abajo.

49 Texto que han utilizado en apoyo de su sugerencia los que proponen la existencia de un juicio, en el cual intervendría Afrodita en apoyo de la muchacha que había seguido sus dictados, como sucede con Apolo en Las Euménides.

so Estas son las líneas generales de la marcha argumental de la trilogía esquilea. No puedo aquí detenerme en mayores puntualizaciones, que podrán verse en la monografia que preparo sobre la obra perdida de Esquilo. 
las dos partes de la futura unidad. Ahora bien, este nuevo planteamiento de la situación no va en contra de que aún en la adaptación esquílea queden restos de viejo esquema amazónico de las hijas de Dánao, de lo cual hay varias huellas en la tragedia conservada, como bien ha visto una parte de la crítica, y tal vez quedaba más de manifiesto en las piezas perdidas, en las que la fiereza de las muchachas se pondría más de manifiesto a la hora de la matanza de sus recién estrenados esposos. La existencia, a mi juicio indiscutible, de esos rasgos amazónicos debe interpretarse como restos de prototipo antiguo, pues es igualmente irrefutable que en Las suplicantes la impronta general es la típica debilidad femenina. Se trataría, pues, de la

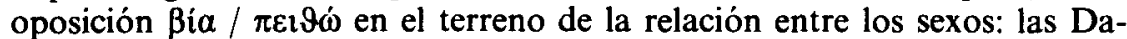
naides rechazan la unión amorosa por la fuerza, como propugnan los Egipcios, $y$ frente a este viejo esquema intentan erigir uno nuevo, la armonía a través de la persuasión.

Esta interpretación viene refrendada maravillosamente por el $F r .44$, que nos transmite Ateneo y que, entre otras cosas, nos certifica que en la última pieza de la trilogía esquílea, en Las Danaides, aparecía en escena la propia Afrodita:

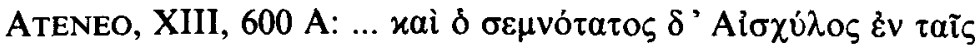

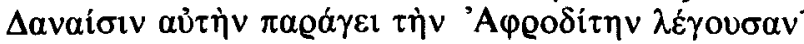

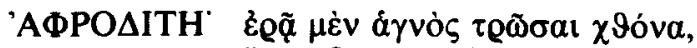

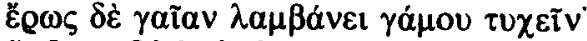

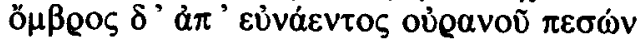

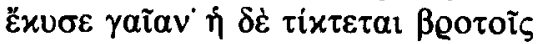

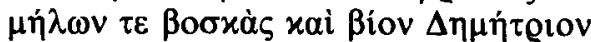

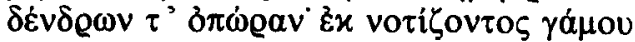

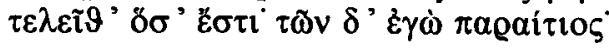

El muy venerable Esquilo en Las Danaides hace intervenir en persona a Afrodita diciendo:

AFRODITA: El sagrado cielo anhela penetrar a la tierra, y el anhelo de alcanzar las bodas se apodera de la tierra. La lluvia cae del fluyente 
cielo y fecunda a la tierra: ella engendra para los mortales pastos de ganados, fruto de Deméter, sazón de los árboles. Producto de las húmedas bodas se hace realidad cuanto existe. De todo ello soy yo la causante.

Este texto formaba parte de un parlamento de la diosa en el que, a todas luces, ésta hacía una apología de la necesidad de la relación entre los sexos. Pero, hay aún más: se trata de una relación armónica, en la que cada una de las partes tiende de grado a la unión con la otra. Y la mejor manera de poner de manifiesto este tipo de atracción es hacer verla funcionando en el contex to cósmico de los componentes esenciales de la naturaleza: el cielo y la tierra. El fragmento esquíleo es de una belleza poética inmensa. No voy a entrar aquí en un comentario textual pormenorizado, sino que sólo me detendré en algunos aspectos que consoliden la interpretación general propuesta. Concretamente, es realmente sorprendente el paralelismo que el poeta consigue en los dos primeros versos, en cada uno de las cuales nos describe la inclinación amorosa de uno y otro componente de la Naturaleza: a parte del meticuloso giro $\mu \dot{\varepsilon} v \ldots \delta \dot{\varepsilon}$, vemos cómo utiliza el mismo término para referirse a la atracción amorosa del Cielo y la Tierra con una pequeña variante morfológica por motivos estilísticos: el Cielo żoã (anhela) frente al ž $\omega \varsigma$ (el anhelo) de la Tierra, y todo ello en principio de verso como términos fundamentales del pensamiento recogido en cada línea; luego encontramos

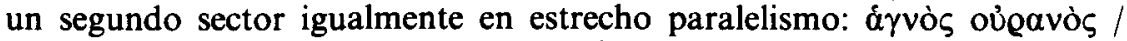
$\gamma \alpha \tilde{\imath} \alpha v \lambda \alpha \mu \beta a ́ v \varepsilon ı$, donde aparecen mencionados los componentes de la sagrada unión (Cielo/Tierra); finalmente, hay una tercera parte de los versos también en estrecha reciprocidad: el objeto del anhelo de cada uno de los

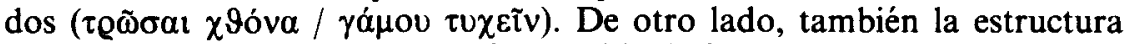
métrica del trímetro yámbico está repartida de forma idéntica en uno y otro verso. Hay, pues, un paralelismo absoluto, y evidentemente buscado, en ambas líneas del texto, y con ello, a mi juicio, Esquilo está queriendo fundamentar su postura de la igualdad y la armonía en las relaciones amorosas como superación del viejo planteamiento.

En el caso de la tetralogía de las Danaides nos encontramos con que también el drama satírico pertenece al mismo contexto mítico y, más aún, plantea la misma problemática de la parte trágica, sólo que ahora en tono jocoso. La pieza cierre se llamaba Amimona, y en ella se trataba de los amores de esta hija de Dánao con Posidón: tras llegar el viejo rey egipcio con sus hijas a Argos, las enviaba, como ya hemos visto, a descubrir fuentes que hiciesen más fertil la «seca» llanura argiva; una de ellas, Amimona, en su marcha por el bosque y mientras cazaba - nuevamente aparecen aquí esos rasgos amazónicos ya mencionados-, es asaltada por Sileno y sus sátiros con intención de violarla, pero la muchacha invoca la ayuda de Posidón que aparece y pone en fuga a los acosadores y, tras persuadirla, se desposa con ella. Una nueva versión, pues, de cómo la unión amorosa debe 
estar guiąda por la «persuasión» y no por la «violencia». De esta forma, también el drama satírico viene en apoyo de la interpretación general que más arriba ha defendido.

En conclusión, la adaptación que Esquilo hizo del mito de las Danaides es un buen ejemplo de en qué gran medida la Tragedia desempeñó un papel fundamental en la evolución del Mito griego, dando entrada a un tratamiento que en muchos casos habría de permanecer vigente en la tradición mitográfica posterior. Y, en este sentido, el estudio de la Tragedia se hace necesario no sólo por razones de interés dramático, como todo género literario, sino también por su incidencia en otras parcelas como ésta del Mito, en cuya interpretación marcaría un jalón decisivo. 